\title{
Diagnostic Three Slides Pap Test Compared to Punch Biopsy and Endocervical Curettage in Confirmed HSIL+ Diagnosis
}

\author{
Roberta Rubeša-Mihaljević ${ }^{1,2, *}$, Danijela Vrdoljak-Mozetič ${ }^{1,2} \oplus$, Morana Dinter ${ }^{1}$, Damjana Verša Ostojić ${ }^{1}$, \\ Snježana Štemberger-Papić ${ }^{1,2}$ and Marko Klarić ${ }^{2,3}$ \\ 1 Department of Pathology and Cytology, Clinical Hospital Center Rijeka, 51000 Rijeka, Croatia; \\ danijela.vrdoljak.mozetic@kbc-rijeka.hr (D.V.-M.); morana.dinter@gmail.com (M.D.); \\ dversa.ostojic@gmail.com (D.V.O.); snjezana.stemberger@ri.t-com.hr (S.Š.-P.) \\ 2 Faculty of Medicine, University of Rijeka, 51000 Rijeka, Croatia; ginekologija@kbc-rijeka.hr \\ 3 Department of Obstetrics and Gynecology, Clinical Hospital Center Rijeka, 51000 Rijeka, Croatia \\ * Correspondence: roberta.rubesa@gmail.com; Tel.: +385-(0)51-658-345; Fax: +385-(0)51-659-427
}

check for

updates

Citation: Rubeša-Mihaljević, R.; Vrdoljak-Mozetič, D.; Dinter, M.; Verša Ostojić, D.; Štemberger-Papić,

S.; Klarić, M. Diagnostic Three Slides Pap Test Compared to Punch Biopsy and Endocervical Curettage in Confirmed HSIL+ Diagnosis. Diagnostics 2021, 11, 942. https:// doi.org/10.3390/diagnostics11060942

Academic Editor: Ivana Kholová

Received: 30 April 2021

Accepted: 22 May 2021

Published: 25 May 2021

Publisher's Note: MDPI stays neutral with regard to jurisdictional claims in published maps and institutional affiliations.

Copyright: (C) 2021 by the authors. Licensee MDPI, Basel, Switzerland. This article is an open access article distributed under the terms and conditions of the Creative Commons Attribution (CC BY) license (https:// creativecommons.org/licenses/by/ $4.0 /)$.

\begin{abstract}
Objective: The aim of the study was to evaluate the accuracy of the diagnostic Pap test (DPT) on three slides and punch biopsy and endocervical curettage (PB/ECC) compared with the final biopsy material in the detection of high-grade squamous intraepithelial lesion (HSIL). Materials and methods: Patients treated with conization after previous DPT and PB/ECC were analyzed. The findings of the DPT and PB/ECC as well as of the endocervical brush cytology and ECC were compared with the final conus histology. Results: 150 patients were analyzed, and final histology verified 145 cases of HSIL and 3 cancers. The percentage of confirmed HSIL cytology was 97\%, while for $\mathrm{PB} / \mathrm{ECC}$ it was $79 \%$ with $30 / 145$ false negative results. The correlation between Pap test and PB/ECC showed that the diagnostic accuracy of DPT is significantly higher $(p<0.0001)$. Endocervical brush cytology confirmed HSIL+ in the endocervical canal in $83 \%$ and ECC in 35\% of cases $(p<0.0001)$. Conclusion: The DPT on three slides enables better detection of HSIL compared to $\mathrm{PB} / \mathrm{ECC}$, particularly for lesions localized in the endocervical canal sampled with a cytobrush. A high quality DPT could represent a surrogate for PB/ECC and open the possibility of direct access to therapeutic procedure.
\end{abstract}

Keywords: diagnostic Pap test; punch biopsy; endocervical curettage; HSIL; final conus histology

\section{Introduction}

Many countries are now moving toward high-risk human papilloma virus (HPV) screening as the primary test in cervical screening [1,2]. Therefore, there is a global tendency to replace the traditional Pap cytology screening of precancerous lesions and cancer with HPV testing due to its higher sensitivity and longer-term protection against high-grade cervical lesions [3,4]. In Croatia, cervical cancer screening has been present since the 1950s mainly as an opportunistic screening with estimated population coverage of $70 \%$. It is performed using a Pap test predominantly as the primary screening test [5] and HPV as an adjunctive triage test. However, at the national level there is a future tendency to introduce HPV testing as a first-line primary screening tool, either simultaneously with cytology or as the only primary test in women aged 30 years or older [6,7].

The expanded use of HPV testing has given a new significance to cytology, which has become more accurate and specialized. It is well known that simultaneous cytological evaluation and HPV analysis significantly increases the efficiency of cervical cancer screening and reduces the overall incidence of invasive cancer [8]. In fact, due to high specificity, ability to identify abnormalities and correct prediction of the final histology outcome, the Pap test is now used as a secondary test, or triage test, after a positive HPV test $[9,10]$. Therefore, cervical cytology is currently even more implemented as a useful diagnostic tool that precedes colposcopy and histological confirmation [11]. 
According to Croatian national guidelines for the management of cervical intraepithelial lesions, colposcopy is recommended in patients with an abnormal Pap test detected in screening programs [12]. Afterwards, in women with colposcopically observed high-grade lesions, punch biopsy and endocervical curettage (PB/ECC) are suggested [12,13]. In the routine diagnostic practice at our institution, the approach to diagnosing cervical lesions includes repeating cytology at the time of colposcopy before doing PB/ECC. Therefore, a Pap test is performed as an additional diagnostic test (DPT). At that point, in order to ensure an optimal specimen that will accurately locate the lesion, cytological samples of the posterior fornix of vagina, ectocervix and endocervix are taken on three separate slides [14]. Furthermore, ancillary testing such as p16/Ki-67 dual staining and HPV testing may be performed in order to achieve the correct diagnosis. This gives the opportunity to the gynaecologist to have simultaneously a DPT and/or PB/ECC report as confirmation of high grade dysplasia before deciding the type of final excision treatment.

In order to assess the role of Pap tests in the management of cervical lesions, especially in the era of primary HPV screening, the aim of this study was to compare the results of DPT and targeted PB/ECC with the final histological diagnosis of squamous high-grade cervical lesions. In addition, the results of the endocervical brush cytology and endocervical curettage were correlated separately with the final histological finding. These results may contribute to determine better the position of cytology as a valuable diagnostic tool in the diagnostic management of cervical dysplasia.

\section{Materials and Methods}

\subsection{Study Population}

The study population was patients referred for colposcopy at the Clinic of Gynaecology and Obstetrics of the Clinical Hospital Centre Rijeka between January 2019 and December 2020 because of an abnormal Pap smear. Inclusion criteria for the study were repeated DPT taken at the time of colposcopy, PB/ECC at the time of colposcopy or in the next visit and subsequent cone biopsy treatment. Patients received large loop excision of the transformation zone (LLETZ) or cold knife cone biopsy treatment for final HSIL+.

\subsection{Methods}

Conventional DPT was taken at the time of colposcopy before histologic examination. The smear was placed on three separate slides representing the samples from the vagina, ectocervix and endocervix. Ayre ectocervical spatula and endocervical brush were used. The convex end of the Ayre spatula was used for the posterior vaginal fornix sampling with semicircular movement. The concave end was used for the ectocervix, and external orifice of the endocervical canal and sampling was done with complete circumference scraping. Endocervical brush cytology was performed by inserting a standard cytobrush to its full depth into the cervical canal. It was then rotated $90^{\circ}$ to $180^{\circ}$. The material was transferred covering the whole glass slide. The slides were fixed in $95 \%$ ethanol and stained by routine Pap staining method. The resulting slides were reviewed and signed out by a cytopathologyst according to The Bethesda System for Reporting Cervical Cytology. HSIL cytological findings were classified positive, while no dysplastic changes or LSIL (low grade squamous intraepithelial lesion) were considered as negative for HSIL. In the group of ASC-H (atypical squamous cells-cannot exclude HSIL) additional testing with p16/Ki-67 dual-staining (CINtec ${ }^{\circledR}$ PLUS Cytology, Roche Diagnostics, Basel, Switzerland) was performed, and the cases were included in the positive group. The location of the dysplastic cells in the specimen was determined semi-quantitatively (ranging from zero to three) to be in posterior fornix, ectocervical or endocervical.

Colposcopy was performed by a gynaecologist certified in colposcopy. Detailed colposcopic examination was performed after the application of $3 \%$ acetic acid. Colposcopic impression was classified as unsatisfactory; negative; abnormal, grade 1 (G1); abnormal, grade 2 (G2); and suspect for invasive cancer. Single or multiple colposcopically directed PB were taken from the worst areas of abnormality together with ECC. ECC was performed 
by placing the Kevorkian metal curette inside the endocervical canal. Gentle pressure was applied at its tip and the curette moved along the length of the endocervix while being rotated in circular way to sample the entire circumference of the canal. Specimens from the endocervical curettage were reviewed microscopically and the amount of endocervical material was described as scant, moderate or abundant.

Loop excision was performed following four-quadrant infiltration of local anaesthetic into the cervix. Specimens obtained by PB, ECC, LLETZ or cold knife cone procedure were immediately fixed in formalin and sent for histological examination. Histological examinations were performed by gynaecological pathologists following a standard protocol. Histological findings on cone specimens were used as the gold standard to measure the performance of the Pap test and colposcopically directed PB and ECC. In the case of HSIL+ diagnosis on $\mathrm{PB}$ and $\mathrm{ECC}$ with consecutive negative cone specimen, histology diagnosis made on PB and ECC was considered final. When multiple biopsies were taken, the highestgrade lesion was used for analysis. Similarly, if cone and LLETZ specimens showed different foci of varying grades of CIN, the worst grade was used as a final diagnosis. The location of the dysplastic process in the conization specimen was determined to be ectocervical or, if present within the endocervical canal, endocervical. Two patients reported as glandular atypia or with coexistence of both squamous and glandular pathology were excluded from the study since only squamous cell lesions were investigated.

\subsection{Statistical Analysis}

Categorical data was expressed as number and percentage. Chi-square $\left(\chi^{2}\right)$ test was applied to compare proportions; $p$ values $<0.05$ were considered statistically significant. Analysis was done with the statistical software MedCalc (MedCalc Software, Version 20, Ostend, Belgium).

\section{Results}

For this study 150 patients met inclusion criteria and were analyzed. The patients' ages ranged from 22 to 71 years with a median of 37 years (Table 1). A total of 127 patients were of reproductive age, and 23 were postmenopausal. Most patients with HSIL-detected lesions were in the age group between 35 and 39 years.

Table 1. Age distribution of patients enrolled.

\begin{tabular}{ccc}
\hline \multirow{2}{*}{ Age (y) } & \multicolumn{3}{c}{ Total Number of Patients } \\
\cline { 2 - 3 } & $\mathbf{N}$ & $\mathbf{( \% )}$ \\
\hline $20-24$ & 10 & $(6.6 \%)$ \\
$25-29$ & 22 & $(14.7 \%)$ \\
$30-34$ & 29 & $(19.3 \%)$ \\
$35-39$ & 40 & $(26.7 \%)$ \\
$40-44$ & 16 & $(10.7 \%)$ \\
$45-49$ & 10 & $(6.6 \%)$ \\
$50-54$ & 7 & $(4.7 \%)$ \\
$55-59$ & 7 & $(4.7 \%)$ \\
$>60$ & 9 & $(6 \%)$ \\
\hline
\end{tabular}

Cytology reports of DPT were evaluated, and the results are shown in Table 2. Most results of DPT were of high-grade dysplasia, including 116 cases of HSIL (77\%), 29 of ASC-H (20\%), 4 of LSIL (2.4\%), 1 case of carcinoma and no ASCUS cytology report. In the group of ASC-H, ancillary testing with $\mathrm{p} 16 / \mathrm{Ki}-67$ dual staining was performed and resulted positive in 16 cases. The distribution of patients' characteristics is shown in Table 2. Colposcopic assessments were recorded for 70 patients and detected mostly grade $1(57 \%)$ and grade 2 lesions (22\%). For colposcopic reports, 14\% were classified as negative and $7 \%$ unsatisfactory, mostly due to the impossibility to visualize the squamocolumnar junction. Patients with abnormal Pap tests were assigned to PB and ECC, and the histologic results 
yielded 15 negative cases with no dysplasia (10\%), 17 LSIL (11\%), 118 HSIL (79\%). Overall, 114 patients underwent LLETZ and 36 cold knife cone biopsy. Out of 150 patients, the final histologic findings confirmed 145 cases of HSIL and 3 cases of microinvasive carcinoma (Table 2).

Table 2. Clinicopathological characteristics of patients.

\begin{tabular}{ccc}
\hline Title & Title & Title \\
\hline Diagnostic Pap Test Findings & & \\
\hline ASCUS & 0 & $(0 \%)$ \\
LSIL & 4 & $(2.4 \%)$ \\
ASC-H & 29 & $(20 \%)$ \\
HSIL & 116 & $(77 \%)$ \\
Carcinoma & 1 & $(0.6 \%)$ \\
\hline Cervical & & \\
Biopsy/Endocervical & & \\
Curettage Findings & & \\
\hline Negative & 15 & $(10 \%)$ \\
LSIL & 17 & $(79 \%)$ \\
HSIL & 118 & $(0 \%)$ \\
Carcinoma & 0 & \\
\hline Colposcopic Findings & & $(14 \%)$ \\
Negative & 10 & $(57 \%)$ \\
Grade 1 (G1) & 40 & $(22 \%)$ \\
Grade 2 (G2) & 15 & $(7 \%)$ \\
Unsatisfactory & 5 & $(1 \%)$ \\
\hline Final histologic Findings & $14 \%)$ \\
\hline Negative & 1 & $(96 \%)$ \\
LSIL & 1 & \\
HSIL & & \\
\hline Carcinoma & & \\
\hline
\end{tabular}

Table 3 shows the results of the DPT compared with the final histological result of LLETZ or cold knife cone biopsy. HSIL cytological findings were classified positive, while no dysplastic changes or LSIL were considered as negative for HSIL. The overall percentage of positive Pap smears confirmed by final histology findings was $97 \%(142 / 146)$. There were only 4 false negative Pap smears confirmed as HSIL by final histology (3\%).

Table 3. Diagnostic Pap test and punch biopsy/endocervical curettage findings compared to final histologic diagnosis. (Abbreviations: DPT: diagnostic Pap test; PB/ECC: punch biopsy/endocervical curettage).

\begin{tabular}{|c|c|c|c|c|c|c|}
\hline \multirow[t]{2}{*}{$\begin{array}{c}\text { Final } \\
\text { Histologic } \\
\text { Diagnosis }\end{array}$} & \multicolumn{2}{|c|}{$\begin{array}{c}\text { DPT Findings } \\
N(\%)\end{array}$} & \multirow[t]{2}{*}{$\begin{array}{c}\text { Total Number } \\
N\end{array}$} & \multicolumn{2}{|c|}{$\begin{array}{c}\text { PB/ECC Findings } \\
N(\%)\end{array}$} & \multirow[t]{2}{*}{$\begin{array}{c}\text { Total Number } \\
N\end{array}$} \\
\hline & Negative & Positive & & Negative & Positive & \\
\hline Negative & 0 & 0 & 0 & 1 & 0 & 1 \\
\hline LSIL & 0 & 1 & 1 & 1 & 0 & 1 \\
\hline HSIL & $4(3 \%)$ & 142 (97\%) & 146 & $30(20 \%)$ & 115 (79\%) & 145 \\
\hline Carcinoma & 0 & 3 & 3 & 0 & 3 & 3 \\
\hline Total & 4 & 146 & 150 & 32 & 118 & 150 \\
\hline
\end{tabular}

Similarly to Pap tests, HSIL findings on PB/ECC were considered positive while no presence of dysplasia and LSIL classified as negative. As shown in Table 3 the agreement or percentage of positive PB/ECC confirmed by final histology was $79 \%(115 / 145)$. Both 
cytology as well as biopsy identified three cases of carcinoma. Interestingly, 30 punch biopsies resulted in false negatives since high-grade dysplasia was confirmed on final histologic diagnosis (20\%).

When the diagnostic accuracy of DPT and PB/ECC was compared, a statistically significant difference was noted. DPT had a significantly higher prediction rate of HSIL lesions when compared to PB/ECC $(p<0.0001)$. Furthermore, biopsies taken at the time of colposcopy often yielded false-negative reports. In fact, the false-negative results were significantly higher among PB/ECC when compared to DPT, thus suggesting a better agreement between cytology and final histology in cone biopsy.

Next, we were interested in whether endocervical brushing might have better diagnostic value compared to ECC for identifying dysplastic lesions when the lesion is located in the endocervical canal. There were 92 cases with simultaneously performed ECC and endocervical brush that were analyzed and compared with the final histologic diagnosis. When the results of the endocervical brush findings were evaluated, $73(83 \%)$ of the 88 patients had high-grade dysplasia in the endocervical sample confirmed on conization (Table 4). However, $17 \%$ of the endocervical cytology reports were interpreted as negative but confirmed as HSIL located in the endocervix on final histology.

Table 4. Endocervical brush and endocervical curettage findings compared with final histologic diagnosis. (Abbreviations: ECC endocervical curettage).

\begin{tabular}{|c|c|c|c|c|c|c|}
\hline \multirow[t]{2}{*}{$\begin{array}{c}\text { Final } \\
\text { Histologic } \\
\text { Diagnosis }\end{array}$} & \multicolumn{2}{|c|}{$\begin{array}{c}\text { Endocervical Brush } \\
\qquad N(\%)\end{array}$} & \multirow[t]{2}{*}{$\begin{array}{c}\text { Total Number } \\
N\end{array}$} & \multicolumn{2}{|c|}{$\begin{array}{c}\text { ECC } \\
N(\%)\end{array}$} & \multirow[t]{2}{*}{$\begin{array}{c}\text { Total Number } \\
N\end{array}$} \\
\hline & Negative & Positive & & Negative & Positive & \\
\hline Negative & 0 & 1 & 1 & 2 & 1 & 3 \\
\hline LSIL & 0 & 1 & 1 & 1 & 2 & 3 \\
\hline HSIL & $15(17 \%)$ & $73(83 \%)$ & 88 & $55(65 \%)$ & $29(35 \%)$ & 84 \\
\hline Carcinoma & 0 & 2 & 2 & 0 & 2 & 2 \\
\hline Total & 15 & 77 & 92 & 58 & 34 & 92 \\
\hline
\end{tabular}

Disagreement between ECC and final histology was also evident. In fact, 65\% of the ECC findings resulted in false negatives when compared to results of cone biopsy (Table 4). We were interested in whether false negative cases of ECC could be due to scant and inappropriate material. Therefore, ECC was analyzed in relation to the amount of endocervical material and quantitated as scant, moderate and abundant. The amount of material found on DPT and the histology tissue section of ECC can be observed in Figure 1. Indeed, $17 \%$ of all ECC samples were classified as scanty or borderline to ensure an accurate interpretation. All samples of endocervical brushed were satisfactory.

Although both DPT and ECC had a considerable level of false negative reports when compared, a significantly higher proportion of false negative results was noted in ECC $(p<0.0001)$. Therefore, the agreement between ECC and conization was only $35 \%$ since ECC detected only 29 HSIL cases out of 84 positive on conization (Table 4). Endocervical brush appeared to have better diagnostic accuracy since the proportion of true positive results was significantly higher when compared to ECC $(p<0.0001)$. 


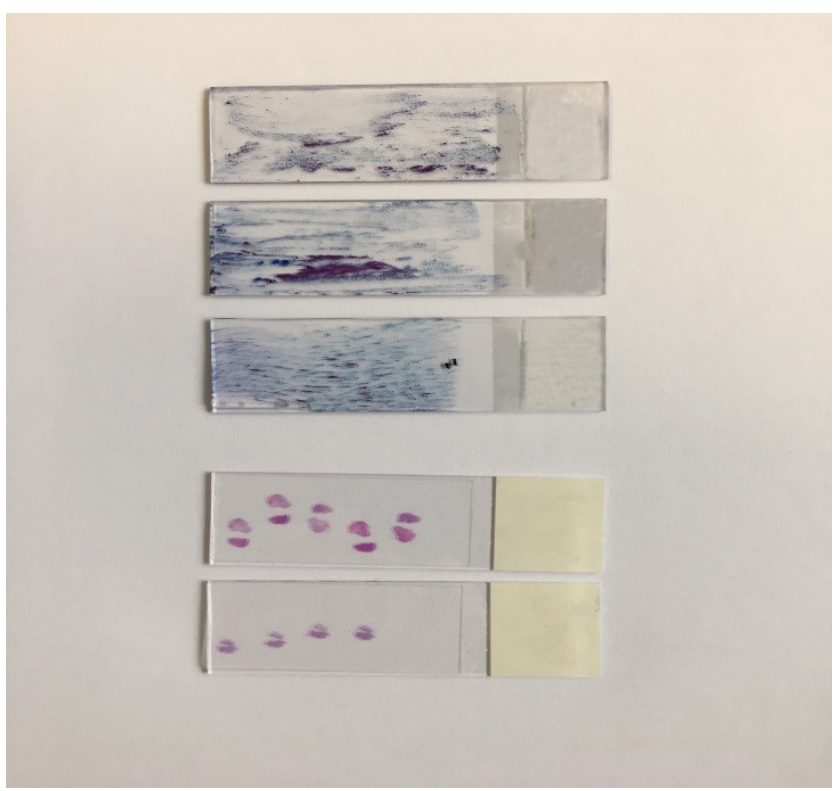

Figure 1. Diagnostic Pap test on three slides and histology tissue section of endocervical curettage material.

\section{Discussion}

In the era of primary HPV screening, cytology has achieved a new role and changed its position from a primary screening tool of a large population to a secondary specialized triage and diagnostic test inevitable in the algorithm of cervical intraepithelial lesions management $[15,16]$. In fact, one of the benefits of primary HPV testing is that HPVnegative patients are unlikely to develop precancerous lesions or cancer and are no longer expected to be referred to cytology [17]. On the other side, with primary HPV screening, a great increase in screen-positive results is expected. Therefore, methods for selecting HPVpositive women, who do not need an immediate colposcopy and have a low probability of carrying a colposcopy-detectable precancerous lesion, are necessary. A triage with cytology appears useful in order to avoid a large number of colposcopy referrals $[18,19]$. At this point, it is expected of cytology to dispose with highly educated and trained personnel as well as ancillary methods, such as immunocytochemistry protocols or cell blocks in order to correctly diagnose, triage and redirect HPV positive or negative patients [18].

The most frequent cause of misdiagnosis in cervical cancer screening is inadequate cervical sampling. The correct sampling of the cervix contributes significantly to the diagnostic value of the Pap test [20]. As previously suggested by other studies to assure an optimal cytological specimen [9,14], gynecologists at our institution have a long-standing practice of performing a DPT on three separate slides by taking the samples from the vagina, ectocervix and endocervix. In fact, our results confirmed that applying this technique offers a diagnostically excellent quality of the Pap test. When the results of the DPT were compared with the final histological result, the overall percentage of high-grade Pap smears confirmed by final histology findings was $97 \%$, with only 4 false-negative results out of 145. To the contrary, the agreement between positive $\mathrm{PB} / \mathrm{ECC}$ and conization was $79 \%$. Other studies have already analyzed discrepancies between the Pap test, PB/ECC and final histology showing similar results. Ihonor et al. [21] confirmed that the agreement between PB and LLETZ was $61 \%$, but according to the authors a significant correlation between PB findings and LLETZ still makes colposcopically directed PB a better predictor of CIN [21]. Other studies indicate that the Pap test is equally sensitive to histopathological examination [22,23]. In our study, DPT confirmed a significantly higher concordance rate of HSIL lesions when compared to PB/ECC.

There is a common perception that, because histology is the "gold standard" of diagnosis, non-correlating cytological results are always wrong. However, cytology offers 
certain advantages over histology in the assessment of cervical dysplasia. Applying the above-mentioned Pap test technique offers a diagnostically better quality sample by providing a greater amount of material and allowing the cytologist to correctly localize the lesion. In addition, previous authors claim that the morphology of intact cells in a cytological preparation is better to interpret subtle abnormalities in comparison to that of sectioned cells in histology that may not be visible in histologic preparations [22]. Finally, a good Pap test samples a broad area, while only a portion of the squamocolumnar junction may be sampled by biopsy [22].

When the results of the endocervical brush and ECC were evaluated, both DPT and ECC had a considerable level of false negative results, with $17 \%$ for endocervical brush and $65 \%$ for ECC. Previous studies have reported that ECC missed $45 \%$ of lesions in the endocervical canal identified on subsequent conization [24]. According to Chrysostomou et al., the false negative rate for ECC was $32.7 \%$ while for endocervical brush it was $8.4 \%$. However, studies indicate that ECC has a higher degree of specificity compared to endocervical brush [17]. There is still no wide agreement on the importance of performing ECC. Factors supporting the necessity to apply ECC consider that ECC can detect lesions that otherwise might be missed by biopsy; ECC identifies lesions in the canal that can be more severe than the one on the portio and is needed for the recognition of a possible endocervical adenocarcinoma $[24,25]$. On the other side, the adequacy of the sample plays an important role in the detection of lesions in the canal. In fact, the inadequacy rate in ECC is high, with reports indicating $22 \%$, mostly because of inefficient sampling and poor recovery of the histologic sections due to tissue processing and dilution [26]. In our study, $17 \%$ of all ECC samples were classified as scanty. Consequently, some authors support the idea that ECC is not indispensable and can be omitted in most instances and replaced by endocervical brush cytology $[24,26]$. Indeed, our results confirmed that the agreement between ECC and conization was only 35\%, while endocervical brush appears to have better diagnostic accuracy since $83 \%$ of cytological HSIL lesions were confirmed in the conization specimen. Besides a higher adequacy rate and higher sensitivity for squamous lesions, recent research confirmed that endocervical brush cytology is more sensitive than ECC for detecting endocervical carcinoma, and with the additional use of a cell block and immunostaining it may be even more helpful [27]. Furthermore, endocervical brush has a higher adequacy rate compared to ECC, it is less expensive and it is associated with less patient discomfort [27].

The lack of concordance between cytology, colposcopically directed PB and subsequent histopathological conization finding is common and remains an important clinical problem. False-negative biopsy or biopsy results that underestimate the grade of CIN may have serious implications if a subsequent conization is not performed [23]. According to the consensus guidelines for the management of abnormal cervical cancer screening tests and cancer precursors released by the American Society for Colposcopy and Cervical Pathology for women with HSIL cytology immediate excisional procedure is acceptable [11] and some authors suggest a "see-and-treat" strategy even in women under age 25 [28]. The results of our study support a similar strategy since they indicate that cytology may offer certain advantages over histology in the assessment of cervical dysplasia. In fact, a wellsampled DPT allows the collection of cells from a broad area of the transformation zone and to localize correctly the lesion. Endocervical brush might replace ECC in evaluating the endocervical canal, particularly in cases when colposcopy is inadequate. Although it is important to remember that both cytology and PB/ECC are diagnostic procedures that are subject to variation in sampling, preparation and interpretation error, a highquality HPV-informed cytology test offers better diagnostic performance and could possibly represent a surrogate for $\mathrm{PB} / \mathrm{ECC}$ in the management of cervical dysplasia in the era of HPV primary testing.

Author Contributions: Conceptualization, D.V.-M. and R.R.-M.; methodology, D.V.O.; experimental investigation, S.Š.-P. and M.D.; validation, M.K.; formal analysis, S.Š.-P. and M.D.; resources, D.V.-M., R.R.-M. and D.V.O.; data curation, M.D. and M.K.; writing-original draft preparation, R.R.-M.; 
writing—review and editing, D.V.-M., S.Š.-P. and M.K.; supervision, D.V.-M., S.Š.-P. and M.K.; project administration, D.V.O. and M.D. All authors have read and agreed to the published version of the manuscript.

Funding: This research received no external funding.

Institutional Review Board Statement: Ethical review and approval were waived for this study due to a retrospective research of patients diagnosed and treated according to national guidelines and agreements using archival data collected as part of routine diagnostic and treatment process, without exposing participants to extraordinary procedures, unnecessary harm or violation of ethical principles and Institutional Review Board procedures.

Conflicts of Interest: The authors declare no conflict of interest.

\section{References}

1. Rebolj, M.; Rimmer, J.; Denton, K.; Tidy, J.; Mathews, C.; Ellis, K.; Smith, J.; Evans, C.; Giles, T.; Frew, V.; et al. Primary cervical screening with high risk human papillomavirus testing: Observational study. BMJ 2019, 364, 1240. [CrossRef]

2. Veijalainen, O.; Kares, S.; Kotaniemi-Talonen, L.; Kujala, P.; Vuento, R.; Luukkaala, T.; Kholová, I.; Mäenpää, J. Primary HPV screening for cervical cancer: Results after two screening rounds in a regional screening program in Finland. Acta Obstet. Gynecol. Scand. 2021, 100, 403-409. [CrossRef]

3. Ronco, G.; Dillner, J.; Elfström, K.M.; Tunesi, S.; Snijders, P.J.F.; Arbyn, M.; Kitchener, H.; Segnan, N.; Gilham, C.; Giorgi-Rossi, P.; et al. Efficacy of HPV-based screening for prevention of invasive cervical cancer: Follow-up of four European randomised controlled trials. Lancet 2014, 383, 524-532. [CrossRef]

4. Gov.UK. Cervical Screening: Implementation Guide for Primary HPV Screening. Available online: https://www.gov.uk/ government/publications / cervical-screening-primary-hpv-screening-implementation/cervical-screening-implementationguide-for-primary-hpv-screening (accessed on 10 April 2021).

5. Vrdoljak-Mozetič, D.; Ostojić, D.V.; Štemberger-Papić, S.; Janković, S.; Glibotić-Kresina, H.; Brnčić-Fischer, A.; Benić-Salamon, K. Cervical cancer screening programme in Primorsko-Goranska County, Croatia-the results of the pilot study. Coll. Antropol. 2010, 34, 225-232.

6. Znaor, A.; Babić, D.; Ćorušić, A.; Grce, M.; Mahovlić, V.; Pajtler, M.; Šerman, A. Prijedlog programa ranog otkrivanja raka vrata maternice u Hrvatskoj. Liječ. Vjesn. 2007, 129, 158-163129.

7. Grce, M.; Grahovac, B.; Rukavina, T.; Vrdoljak-Mozetič, D.; Glavaš-Obrovac, L.; Kaliterna, V.; Zele-Starčević, L. HPV testing for cervical cancer screening in Croatia. Coll. Antropol. 2007, 31, 67-71.

8. Grce, M.; Sabol, I.; Milutin Gašperov, N. Burden and prevention of HPV related diseases: Situation in Croatia. Period. Biol. 2012, $114,175-186$.

9. Xie, F.; Zhang, L.; Zhao, D.; Wu, X.; Wei, M.; Zhang, X.; Wu, X.; Fang, H.; Xu, X.; Yang, M.; et al. Prior cervical cytology and high-risk HPV testing results for 311 patients with invasive cervical adenocarcinoma: A multicenter retrospective study from China's largest independent operator of pathology laboratories. BMC Infect. Dis. 2019, 19, 962. [CrossRef]

10. von Karsa, L.; Arbyn, M.; De Vuyst, H.; Dillner, J.; Dillner, L.; Franceschi, S.; Patnick, J.; Ronco, G.; Segnan, N.; Suonio, E.; et al. European guidelines for quality assurance in cervical cancer screening. Summary of the supplements on HPV screening and vaccination. Papillomavirus Res. 2015, 1, 22-31. [CrossRef]

11. Stelow, E.B.; Gulbahce, H.E.; Kjeldahl, K.; Oprea, G.M.; Savik, K.; Pambuccian, S.E. Interpretive yields of screening Pap tests and diagnostic Pap tests. Diagn. Cytopathol. 2004, 31, 427-429. [CrossRef]

12. Perkins, R.B.; Guido, R.S.; Castle, P.E.; Chelmow, D.; Einstein, M.H.; Garcia, F.; Huh, W.K.; Kim, J.J.; Moscicki, A.B.; Nayar, R.; et al. 2019 ASCCP Risk-Based Management Consensus Guidelines for Abnormal Cervical Cancer Screening Tests and Cancer Precursors. J. Low. Genit. Tract Dis. 2020, 24, 102-131. [CrossRef]

13. Croatian Society of Gynecology and Obstetrics. Cervikalne Intraepitelne Lezije: Smjernice za Dijagnostiku i Liječenje. Available online: https: / / www.hdgo.hr/Default.aspx?sifraStranica=642 (accessed on 5 April 2021).

14. National Cancer Control Plan 2020-2030. Available online: https://www.nppr.hr/wp-content/uploads/2020/01/NPPR_ENG_ final.pdf (accessed on 5 April 2021).

15. Chen, C.J.; Hong, M.K.; Ding, D.C. Effective reduction in inadequate Pap smears by using a saline-lubricated speculum and two glass slides. Taiwan. J. Obstet. Gynecol. 2020, 59, 906-909. [CrossRef]

16. Gultekin, M.; Dundar, S.; Keskinkilic, B.; Turkyilmaz, M.; Ozgul, N.; Yuce, K.; Kara, F. How to triage HPV positive cases: Results of four million females. Gynecol. Oncol. 2020, 158, 105-111. [CrossRef]

17. Isidean, S.D.; Mayrand, M.H.; Ramanakumar, A.V.; Rodrigues, I.; Ferenczy, A.; Ratnam, S.; Coutlée, F.; Franco, E.L.; CCCaST Study Group. Comparison of Triage Strategies for HPV-Positive Women: Canadian Cervical Cancer Screening Trial Results. Cancer Epidemiol. Biomark. Prev. 2017, 26, 923-929. [CrossRef]

18. Chrysostomou, A.C.; Kostrikis, L.G. Methodologies of Primary HPV Testing Currently Applied for Cervical Cancer Screening. Life 2020, 10, 290. [CrossRef] 
19. Bergeron, C.; von Knebel Doeberitz, M. The Role of Cytology in the 21st Century: The Integration of Cells and Molecules. Acta Cytol. 2016, 60, 540-542. [CrossRef]

20. Rijkaart, D.C.; Berkhof, J.; van Kemenade, F.J.; Coupe, V.M.; Hesselink, A.T.; Rozendaal, L.; Heideman, D.A.; Verheijen, R.H.; Bulk, S.; Verweij, W.M. Evaluation of 14 triage strategies for HPV DNA-positive women in population-based cervical screening. Int. J. Cancer 2012, 130, 602-610. [CrossRef]

21. Lukic, A.; Iannaccio, S.; Heyn, R.; Villani, S.; Nobili, F.; Giarnieri, E.; Mancini, R.; Moscarini, M.; Giovagnoli, M.R. Satisfactory sampling in cytological cervical diagnosis: Comparison between a conventional and a new sampling device. Anticancer Res. 2013, 33, 917-922.

22. Ihonor, A.O.; Cheung, W.Y.; Freites, O.N. A comparative study of the assessment of cervical intraepithelial neoplasia in women having large loop excision of the transformation zone. J. Obstet. Gynaecol. 1999, 19, 169-171. [CrossRef]

23. Al-Mosawi, F.H. Comparative Study of Pap Smear and Cervical Biopsy Findings. Kerbala J. Med. 2015, 8, $2272-2281$.

24. Aydogmus, H.; Sen, S.; Aydogmus, S. Pathological discrepancy between colposcopic directed cervical biopsy and conisation results: A five years experience of a single center in Turkey. Pak. J. Med. Sci. 2019, 35, 1627-1630. [CrossRef] [PubMed]

25. Driggers, R.W.; Zahn, C.M. To ECC or not to ECC: The question remains. Obstet. Gynecol. Clin. N. Am. 2008, 35, 583-597. [CrossRef] [PubMed]

26. Andersen, W.; Frierson, H.; Barber, S.; Tabbarah, S.; Taylor, P.; Underwood, P. Sensitivity and specificity of endocervical curettage and the endocervical brush for the evaluation of the endocervical canal. Am. J. Obstet. Gynecol. 1988, 159, 702-707. [CrossRef]

27. Zou, T.; Dave, S.; Adler, R.N.; Manning, M.J.; Scott, M.P.; Strock, C.; Kandil, D.; Cosar, E.; Fischer, A.H. Colposcopic endocervical brushing cytology appears to be more sensitive than histologic endocervical curettage for detecting endocervical adenocarcinoma. J. Am. Soc. Cytopathol. 2021, 10, 135-140. [CrossRef] [PubMed]

28. Smith, H.J.; Leath, C.A., 3rd; Huh, W.K.; Erickson, B.K. See-and-Treat for High-Grade Cytology: Do Young Women Have Different Rates of High-Grade Histology? J. Low. Genit. Tract Dis. 2016, 20, 243-246. [CrossRef] [PubMed] 